\title{
Intrapulmonary teratoma 10 years after removal of a mediastinal teratoma in a young man
}

\author{
HW PRÄUER, D MACK, R BABIC
}

From the Department of Thoracic Surgery and Institute of Pathology, Klinikum Rechts der Isar, Technical University, Munich

Teratoma is a common tumour of the mediastinum but is rarely found in the lung. The twentieth reported case was published in 1975 by Day and Taylor and four cases have been published since..$^{-5} \mathrm{~A}$ rare condition, not previously recorded, was observed by us in a young male patient. He was found to have a mediastinal teratoma, which was followed $\mathbf{1 0}$ years later by the growth of an intrapulmonary teratoma.

\section{Case report}

A 14-year-old boy was admitted to our thoracic unit for the first time in 1970 with an opacity in the right pleural cavity detected on a routine chest film. He had noticed intermittent pain in the right chest radiating to the arm and a non-productive cough. The chest radiograph showed a solid mass of varying density $10 \mathrm{~cm}$ in diameter just above the right diaphragm and adjacent to the right cardiac border (fig 1a). Tomography showed calcification and cystic areas. Routine laboratory investigations and bronchoscopy gave normal results. Posterolateral thoracotomy was performed and a firm mass with a knobbly surface was found in the lower anterior mediastinum. The tumour was pedunculated, arising from the upper mediastinum and receiving an additional blood supply from branches of the internal mammary artery. It was excised without difficulty and the patient made an uneventful postoperative recovery.

The operative specimen was a nodular tumour measuring $13 \times 12 \times 7 \mathrm{~cm}$. The cut surface showed several cavities containing sebaceous material and hair, surrounded by areas of hyaline tissue, bone, and cartilage. On microscopic examination some cystic cavities were seen to be lined by squamous epithelium with sebaceous glands and hair follicles and others by respiratory and intestinal epithelium. Sections from various points showed connective tissue, hyaline cartilage, and fat tissue. In one nodular area epithelial strands and tubuli surrounded by immature mesenchyme were found. There was no evidence of malignant change in any part of the tumour. The diagnosis was benign cystic teratoma of the mediastinum.

Ten years later the patient reappeared with a five-month history of recurrent bronchopneumonia unresponsive to

Address for reprint requests: Dr HW Präuer, Chirurgische Klinik und Poliklinik der Technischen Universität München, Ismaninger Strasse 22, D-8000 München 80, W Germany.

Accepted 9 February 1983

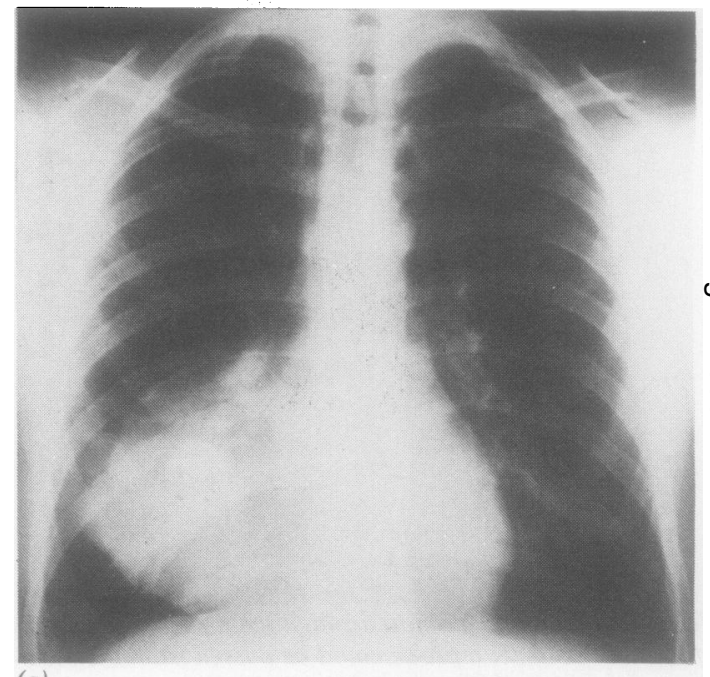

(a)

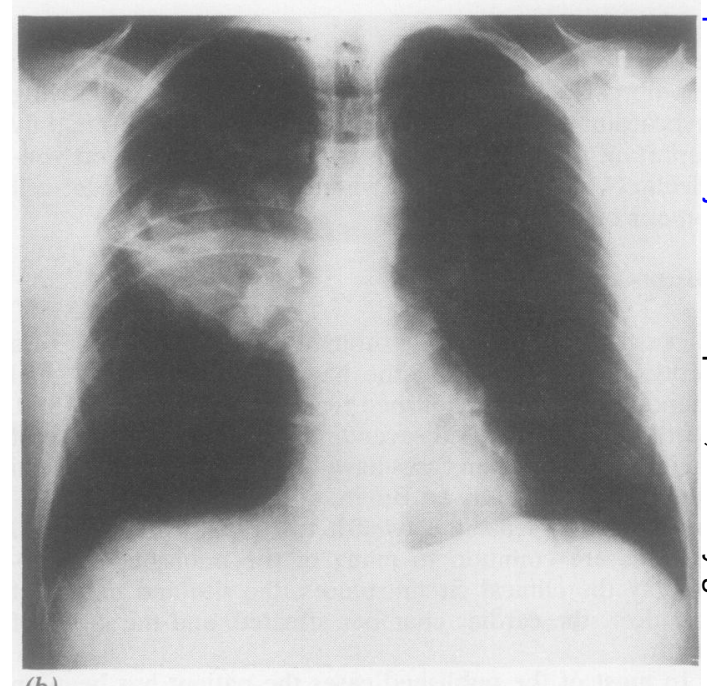

(b)

Fig 1 Chest radiographs showing (a) an opacity in the right lower anterior mediastinum (1970) and (b) a cystic mass in the right upper lobe with focal calcifications (1980) 
antibiotics. Chest radiographs showed an opacity in the right upper lobe $9 \mathrm{~cm}$ in diameter with cystic areas and calcification. The shadow was strikingly similar in configuration and structure to that found in 1970 (fig $1 b$ ). The haemoglobin concentration was $14.8 \mathrm{~g} / \mathrm{dl}$, the white blood cell count $9 \cdot 1 \times 10^{\%} / 1$, and the erythrocyte sedimentation rate $120 \mathrm{~mm}$ in the first hour. The concentration of serum $\alpha$-fetoprotein was raised (192 $\mathrm{ng} / \mathrm{ml}$ ) but that of carcinoembryonic antigen was normal. Bronchoscopy showed purulent discharge from the orifice of the right upper-lobe bronchus and a tuft of hair protruding into the lumen. Scans of liver, skeleton, and brain were normal. Intrapulmonary teratoma was suspected and another thoracotomy was performed. After partial extrapleural dissection a solid tumour was palpable in the anterior segment of the right upper lobe, densely adherent to the middle lobe and the pericardium. For complete excision bilobectomy (right upper and middle lobe) and partial pericardectomy had to be performed.

The right upper lobe was occupied by an encapsulated, partially cystic mass $8 \mathrm{~cm}$ in diameter. The cut surface showed hair and sebaceous material within the cavities and bony areas in the surrounding tissue (fig $2 a$ ). The middle lobe was collapsed.

Histologically well differentiated structures of epithelial and mesenchymal origin were present. There were cavities lined with squamous epithelium and others with respiratory epithelium. Areas of smooth muscle, fat, cartilage, pancreatic acinar tissue, and fetal lung (fig $2 b$ ) could be identified. The diagnosis was a predominantly mature but partially immature intrapulmonary teratoma.

The postoperative course was uncomplicated. The $\alpha$-fetoprotein concentration has gradually returned to normal and has remained so during a follow-up period of 28 months.

\section{Discussion}

Several well-documented cases of intrapulmonary teratoma have been published in recent years, and the clinicopathological features have been delineated and its possible origins discussed..$^{1-7}$ We confine ourselves to

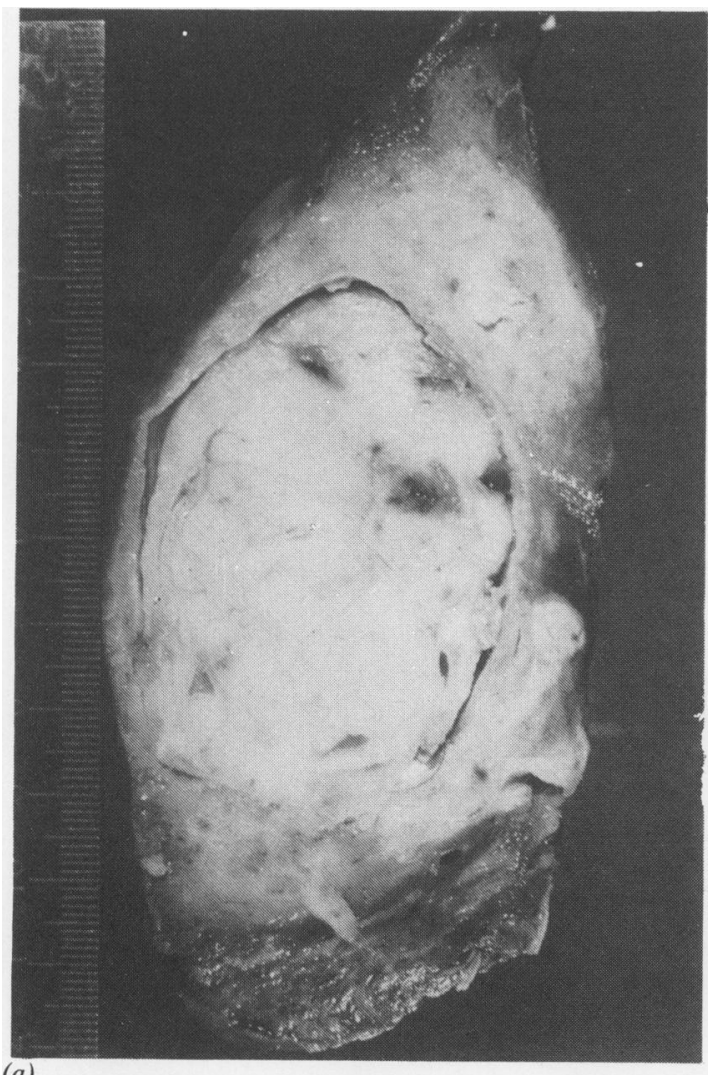

(a)

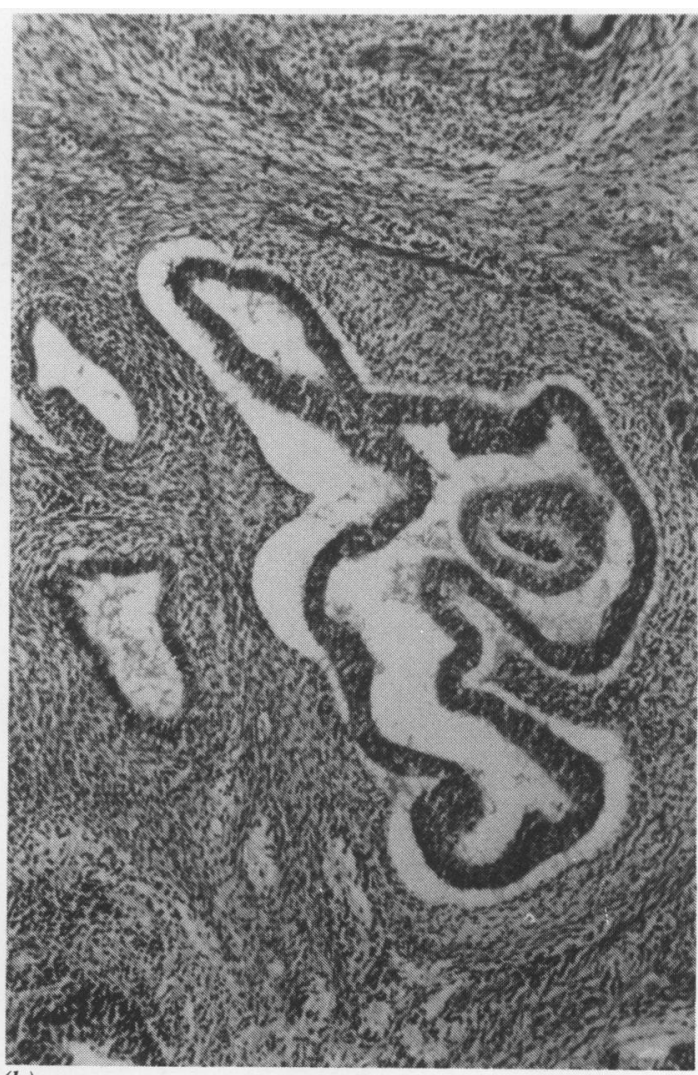

(b)

Fig 2 (a) Cross-section of the operative specimen showing the well-encapsulated intrapulmonary teratoma. (b) Section from another part of the tumour showing fetal lung. (Haematoxylin and eosin, $\times 16$. 
drawing attention to some unusual aspects of the case we describe.

Firstly, this patient had teratomas developing both in the mediastinum and in the lung. The second tumour developed independently of the first, although a common origin from aberrant tissue of the third pharyngeal pouch may be assumed. ${ }^{6}$ Secondly, the bronchoscopic demonstration of hair in the bronchial tree-equivalent to the rare symptom of expectoration of hair (trichoptysis) -led to the preoperative diagnosis of intrapulmonary teratoma. ${ }^{258}$ Thirdly, the appearance of the second tumour was associated with a raised serum $\alpha$-fetoprotein concentration, which returned to normal after removal of the tumour. Evidence of its origin from tumour tissue was obtained by immunocytochemical labelling (PAP reaction). ${ }^{9}$ Alphafetoprotein is typically produced in hepatocytes, yolk sac cells, and probably also certain cells of the primitive gut. Recently a primary lung cancer producing $\alpha$-fetoprotein was observed. ${ }^{10}$ To our knowledge an $\alpha$-fetoproteinproducing intrathoracic teratoma has not been reported previously. Our observations may be consistent with the theory of the origin of thoracic teratoma from tissue of the upper primitive gut.

\section{References}

' Day DW, Taylor SA. An intrapulmonary teratoma associated with thymic tissue. Thorax 1975;30:582-7.

${ }^{2}$ Kravetz VM, Kamentsky MC, Efdaha PN, Ilivsky IP. Intrabron chial teratoma. Klin Khir 1976;8:54-5.

${ }^{3}$ Holt S, Deverall PB, Boddy JE. A teratoma of the lung contain ing thymic tissue. J Pathol 1978;126:85-9

4 Eckert VM, Gerassimidis T. Intrapulmonales Teratom. Fall $\mathcal{S}$ bericht und Literaturübersicht. Fortschr Med 1979.뭉 97:1051-4.

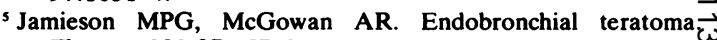
Thorax 1982;37:157-9.

' Bateson EM, Hayes JA, Woo-Ming M. Endobronchial teratoma associated with bronchiectasis and bronchiolectasis. Thorax 1968;23:69-76.

${ }^{7}$ Gautam HP. Intrapulmonary malignant teratoma. Am Rev Respir Dis 1969;100:863-5.

${ }^{8}$ Laffitte MH. Embryome tératoide intra-pulmonaire. Exérèse erru un temps. Mem Acad Chir 1937;63:1076-85.

${ }^{9}$ Sternberger LA. Immunocytochemistry. 2nd ed. New York: John음 Wiley and Sons, 1979:104-69.

10 Yasunami R, Hashimoto Z, Ogura T, Yamamura Y. Primary lung cancer producing alpha-fetoprotein. Cancer 1981 47:926-9. 